
Kidney
Bloód Pressure Research

Kidney Blood Press Res 2015;40:424-434

\begin{tabular}{l|l}
\hline DOI: $10.1159 / 000368518$ & (c) 2015 S. Karger AG, Basel
\end{tabular}

www.karger.com/kbr

Accepted: June 23, 2015

1423-0143/15/0404-0424\$39.50/0

This is an Open Access article licensed under the terms of the Creative Commons AttributionNonCommercial 3.0 Unported license (CC BY-NC) (www.karger.com/OA-license), applicable to the online version of the article only. Distribution permitted for non-commercial purposes only.

\title{
Common Variants in Serum/Glucocorticoid Regulated Kinase 1 (SGK1) and Blood Pressure Responses to Dietary Sodium or Potassium Interventions: A family-Based Association Study
}

\author{
Chao Chu ${ }^{a, b}$ Yang Wang ${ }^{a, b}$ Man Wang ${ }^{a}$ Jian-jun Mu ${ }^{a, b} \quad$ Fu-qiang Liu a,b \\ Lan Wang $^{a}$ Ke-yu Ren ${ }^{a, b}$ Dan Wang ${ }^{a, b}$ Zu-yi Yuan ${ }^{a, b}$
}

${ }^{a}$ Department of Cardiovascular medicine, First Affiliated Hospital of Medical College, Xi'an Jiaotong

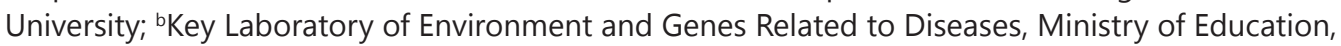
Xi'an, P.R. China

\section{Key Words}

Serum/glucocorticoid regulated kinase 1 - Blood pressure - Sodium • Potassium • Singlenucleotide polymorphism

\begin{abstract}
Background/Aims: Serum/Glucocorticoid Regulated Kinase 1 (SGK1) plays a significant role in regulating renal $\mathrm{Na}^{+}$reabsorption, $\mathrm{K}^{+}$secretion, and blood pressure (BP). This study aimed to assess the association of common genetic variants in the SGK1 gene with BP responses to controlled dietary sodium or potassium interventions. Methods: A total of 334 subjects from 124 families were recruited from the rural areas of northern China. After a three-day baseline observation, they were sequentially maintained a seven-day low-sodium diet $(3 \mathrm{~g} / \mathrm{day}$ of $\mathrm{NaCl}$ or $51.3 \mathrm{mmol} /$ day of sodium), a seven-day high-sodium diet (18g/day of $\mathrm{NaCl}$ or $307.8 \mathrm{mmol} /$ day of sodium) and a seven-day high-sodium plus potassium supplementation intervention $(4.5 \mathrm{~g} /$ day of $\mathrm{KCl}$ or $60 \mathrm{mmol} /$ day of potassium). Six single-nucleotide polymorphisms (SNPs) in the SGK1 gene were selected. Results: After adjustment for multiple testing, SNP rs9376026 was significantly associated with diastolic BP (DBP) and mean arterial pressure (MAP) responses to low-sodium intervention ( $P=0.018$ and 0.022 , respectively). However, the associations between selected SNPs in the SGK1 gene and BP responses to high-sodium or high-sodium plus potassium-supplementation intervention did not reach statistical significance. In addition, SNP rs9389154 and two other SNPs (rs1763509 and rs9376026) were associated respectively with systolic BP (SBP) and DBP at baseline $(P=0.040,0.032$, and 0.031 , respectively). SNP

C. Chu, Y. Wang and M. Wang contributed equally to this work and therefore share first authorship.




\section{Kidney Blood Pressure Research}

Kidney Blood Press Res 2015;40:424-434

DOI: $10.1159 / 000368518$

Published online: July 31, 2015

(C) 2015 S. Karger AG, Base

www.karger.com/kbr

rs3813344 was significantly associated with SBP, DBP, and MAP $(P=0.049,0.015$ and 0.018 , respectively). Conclusion: Our study indicates that the genetic polymorphism in the SGK1 gene is significantly associated with BP responses to dietary sodium intervention.

Copyright (C) 2015 S. Karger AG, Basel

\section{Introduction}

High blood pressure (BP) is the leading preventable risk factor for cardiovascular diseases, accounting for approximately $47 \%$ of ischemic heart diseases and $54 \%$ of strokes worldwide [1]. Interactions among numerous genetic and environmental factors play an important role in BP regulation. Observational epidemiologic studies have reported that $\mathrm{BP}$ is positively correlated with dietary sodium intake and inversely associated with dietary potassium intake [2-4]. However, BP responses to dietary sodium intake or potassium supplementation vary considerably among individuals [5, 6]. Sizeable evidence suggests that the genetic profile of an individual may contribute to this phenomenon $[6,7]$. Thus, discovering novel genetic variants related to BP responses to dietary sodium or potassium intake can help us better understand the biological mechanisms of BP regulation.

Serum/glucocorticoid regulated kinase 1 (SGK1), a member of the AGC family of serine/threonine protein kinases, was first identified as a gene transcriptionally controlled by serum and glucocorticoids in rat Con8 mammary epithelial tumor cells [8]. The gene (148, $813 \mathrm{bp}$ ) contains 17 exons and is located on chromosome 6 at q23 (Gene ID: 6446). The SGK1 protein is expressed in virtually all tissues, predominantly in those involved in water and electrolyte reabsorption, such as renal and colonic mucosa $[9,10]$. Accordingly, SGK1 contributes to a variety of pathological processes, such as renal tissue fibrosis, colonic tumor growth, vascular inflammation, and atherogenesis [11-13]. Moreover, it participates in the regulation of renal sodium reabsorption, potassium elimination and thus potentially blood pressure by aldosterone, which affects various transport systems, including $\mathrm{Na}^{+}$/ $\mathrm{H}^{+}$exchanger 3 in proximal tubule, epithelial $\mathrm{Na}^{+}$channel, $\mathrm{Na}^{+}-\mathrm{Cl}^{-}$cotransporter, and renal outer-medullary $\mathrm{K}^{+}$channel 1 in distal convoluted tubule and collecting duct, and basolateral $\mathrm{Na}^{+}-\mathrm{K}^{+}$-ATPase in all nephron segments [14-18]. Animal studies showed that, compared with wild-type mice, SGK1-knockout (SGK1 ${ }^{-/}$) mice have higher urinary flow rate, increased $\mathrm{Na}^{+}$ excretion, hyperkalemia, lower BP, and significantly increased plasma aldosterone levels under a low- $\mathrm{Na}^{+}$diet [19]. Epidemiological studies also found an association between a certain SGK1 gene variant (combined polymorphisms in intron 6 [I6CC] and in exon 8 [E8CC/CT]) and moderately enhanced BP in white Germans [20]. These data suggested that SGK1 genetic variants contribute to BP variations and/or to susceptibility to essential hypertension. However, few studies considered the gene and environment interactions, especially dietary salt and potassium, on BP. Owing to the interference between gene and environment interactions, the genetic contribution to BP variability is difficult to detect fully in those studies. In view of this limitation, our study aimed to assess the association of common genetic variants in the SGK1 gene with BP responses to controlled dietary sodium or potassium interventions of 334 normotensive or pre-hypertensive subjects from rural northern China.

\section{Participants and Methods}

\section{Subjects}

This investigation involved a family-based dietary feeding study conducted in a Han Chinese population from the rural areas of northern China. The potential probands and their families were identified by a community-based BP screening conducted among adults aged 18-60 years in the study villages. The 


\section{Kidney \\ Blood Pressure Research}

Kidney Blood Press Res 2015;40:424-434

\begin{tabular}{l|l}
\hline DOI: $10.1159 / 000368518$ & (C) 2015 S. Karger AG, Basel
\end{tabular}

Published online: July 31, 2015

www.karger.com/kbr

Chu/Wang/Wang/Mu/Liu/Wang/Ren/Wang/Yuan: SGK1 and BP Responses to Dietary Interventions

probands who had a mean systolic BP (SBP) between 130-160 mmHg and/or a diastolic BP (DBP) between 85-100 mmHg and no use of antihypertensive medications and their siblings, spouses, and offspring were recruited for the dietary intervention study. The exclusion criteria were secondary hypertension, stage-2 hypertension, a history of clinical cardiovascular disease or diabetes, used antihypertensive medications, or were pregnant, heavy alcohol drinkers, or currently on a low-sodium diet, or unable to sign the informed consent form.

The institutional ethics committee of Xi'an Jiaotong University Medical School approved the study protocol, and written informed consent for the baseline observation and for the intervention program was obtained from each participant. All of the procedures were performed in accordance with institutional guidelines.

\section{Dietary intervention}

The chronic salt loading and potassium-supplementation intervention program was carried out as previously described [21]. Briefly, after a three-day baseline examination including a questionnaire survey and measurements of BP, height, weight and blood biochemical parameters, the study participants sequentially received a seven-day low-sodium diet ( $3 \mathrm{~g} /$ day of $\mathrm{NaCl}$ or $51.3 \mathrm{mmol} /$ day of sodium), a sevenday high-sodium diet (18g/day of $\mathrm{NaCl}$ or $307.8 \mathrm{mmol} /$ day of sodium) and a seven-day high-sodium plus potassium supplementation intervention $(4.5 \mathrm{~g} /$ day of $\mathrm{KCl}$ or $60 \mathrm{mmol} /$ day of potassium). All foods were cooked without salt, and prepackaged salt was added to the meal of each participant when it was served by the study staff. During the entire study period, other dietary nutrient intakes remained unchanged. To ensure the compliance of participants to the intervention program, they were required to have their three meals (breakfast, lunch, and dinner) in the study kitchen. The participants were also given detailed instructions to avoid consuming food not provided by the study.

\section{Determination of 24-hour urinary sodium and potassium excretions}

One 24-hour urinary specimen was collected at baseline and the end of each intervention period to ensure the compliance of participants to the dietary intervention. The concentrations of sodium and potassium in the urine sample were measured by a flame photometer. The 24-hour urinary sodium and potassium excretions of each subject were calculated as the measured concentration of sodium or potassium multiplied by total volume of individual's 24-hour urine.

\section{BP measurements}

Three BP measurements were obtained using a random-zero sphygmomanometer (Hawksley \& Sons Ltd, Lancing, UK) at each morning of 3-day baseline examination as well as on days 5, 6, and 7 of each dietary period, and BP was measured by the trained and certified observers according to a common protocol [22]. Study participants were required to avoid cigarette smoking, alcohol, coffee/tea, and Strenuous exercise for at least 30 minutes before their BP measurement. BP measurement was taken in a sitting position after a 5-min rest. The first and fifth phases of the Korotkoff sounds were taken as SBP and DBP, respectively. Three BP measurements each day were performed with an interval of 1-min and the mean values of nine BP measurements during the baseline survey or each intervention period were recorded as the BP levels at baseline and each intervention period. In addition, MAP was calculated according to the following formula: $\mathrm{MAP}=\mathrm{DBP}+1 / 3$ (SBP-DBP). In the present study, BP responses were considered as continuous variables and defined as follows: BP response to low sodium = BP on low-sodium diet minus BP at baseline; BP response to high sodium $=\mathrm{BP}$ on high-salt diet minus $\mathrm{BP}$ on low-salt diet; and BP response to potassium supplementation = BP on high-salt diet with potassium supplementation minus BP on high-salt diet.

\section{SGK1 SNP Selection and Genotyping}

Six tagSNPs in the SGK1 gene with a minor allele frequency (MAF) of more than $5 \%$ in the Chinese Han of Beijing HapMap databank (www.hapmap.org/) were selected as the study sites. Genomic DNA was extracted from whole blood specimen collected from each participant using the GOLDMAG Whole Blood Genomic DNA Purification Kit (Golden Magnetic Nano-Biotechnology Co., Ltd. Xi'an, China). PCR primers and single base extension primers required for SNP genotyping were designed by MassARRAY Assay 


\section{Kidney Blood Pressure Research}

Kidney Blood Press Res 2015;40:424-434

\begin{tabular}{l|l}
\hline DOI: $10.1159 / 000368518$ & (c) 2015 S. Karger AG, Basel
\end{tabular}

Published online: July 31, 2015

www.karger.com/kbr

Chu/Wang/Wang/Mu/Liu/Wang/Ren/Wang/Yuan: SGK1 and BP Responses to Dietary Interventions

Design software (version 3.0) and synthesized by Shanghai Biological Technology Co., Ltd. (http://www. sangon.com/). The genotyping experiments were done by Xi'an BaiMei genetic testing center (http://www. lifegen.com/) using a MassARRAY system (Sequenom, San Diego, CA, USA) based on the matrix-assisted laser desorptionionization time-of-light mass spectrometry method, according to the manufacturer's instructions. Genotype calling was performed in real time with MassARRAY RT software (version 3.1) and analyzed using the MassARRAY Typerrt software version 4.0 (Sequenom).

Statistical analysis

Continuous data are presented as mean \pm standard error. Categorical data are expressed as frequency with percentage. Differences in repeated measures were analyzed by Paired samples t-test. The Mendelian consistency of the single-nucleotide polymorphism (SNP) genotype data was assessed using PLINK [23]. We used Haploview software (version 4.0, http://www.broad.mit.edu/mpg/haploview) to test HardyWeinberg equilibrium on parental SNP data and estimate the extent of pairwise linkage disequilibrium (LD) between SNPs. LD blocks were defined using the solid spine LD method implemented in Haploview software [24]. The association of single markers with adjusted phenotypes was investigated using a family-based association test (FBAT; version 2.0.2, http://www.biostat.harvard.edu/fbat /default. html) and three genetic models (additive, dominant, and recessive) were adopted in each SNP analysis [25]. To assess the effect of genetic variants on the trait value, a univariate FBAT test was performed for each allele and haplotype. This test provides a Z-statistic with its corresponding P-value. In the present study, a positive Z-statistic for an allele or a haplotype indicated a decreased response to the low-sodium intervention and high-sodium plus potassium-supplementation intervention, an increased response to high-sodium intervention, and an increase in basal BP. The false discovery rate (FDR) method was used to correct for multiple testing [26]. A q-value of 0.05 was the threshold for statistical significance in our study.

\section{Results}

Baseline characteristics and BP responses to dietary intervention

Table 1 shows the baseline characteristics and BP responses to the low-sodium, high-sodium, and high-sodium plus potassium-supplementation interventions of study participants. The mean levels of baseline systolic BP (SBP), diastolic BP (DBP), and mean arterial pressure (MAP) in the proband group were higher than those in the sibling, spouse, and offspring groups. The baseline SBP level of the parent group, however, was the highest among those of all the groups. Overall, BP levels were reduced and increased respectively in response to the low-sodium and high-sodium interventions, and BP levels were again reduced in response to the high-sodium plus potassium-supplementation intervention.

Influence of dietary intervention on 24-hour urinary sodium and potassium excretions

The influence of dietary intervention on 24-hour urinary sodium and potassium excretions are shown in Table 2. To ensure the compliance of participants to the intervention program, the sodium and potassium values in 24-hour urine were calculated at baseline and at the end of each diet period. The 24-hour urinary sodium and potassium excretions at baseline indicated that the diet of the participants featured high sodium and low potassium. The 24-hour urinary sodium excretion reduced from baseline to low-sodium diet but markedly increased from low-sodium to high-sodium diet. The 24-hour urinary sodium and potassium excretions were slightly increased by high-sodium and potassium supplementation. This result showed excellent compliance with the dietary intervention.

Information on genotyped SNPs in SGK1

Table 3 shows the information on the genotyped SNPs in SGK1, including genomic location, allele frequency, and Hardy-Weinberg equilibrium test results for the six SNPs in SGK1. No SNP deviated from the Hardy-Weinberg equilibrium $(P>0.05)$. 


\section{Kidney \\ Blood Pressure Research}

\section{Kidney Blood Press Res 2015;40:424-434}

DOI: $10.1159 / 000368518$

Published online: July 31, 2015

(C) 2015 S. Karger AG, Basel

www.karger.com/kbr

Table 1. Characteristics of participants

\begin{tabular}{|c|c|c|c|c|c|c|}
\hline & Probands & Siblings & Spouses & Offspring & Parents & Non-parents ${ }^{\dagger}$ \\
\hline NO. of subjects & 99 & 167 & 19 & 49 & 181 & 334 \\
\hline Age, year & $41.8 \pm 8.4$ & $39.8 \pm 7.4$ & $47.4 \pm 6.1$ & $23.3 \pm 6.9$ & $66.1 \pm 8.3$ & $38.4 \pm 9.9$ \\
\hline Male, $\%$ & 69.7 & 49.1 & 26.3 & 49.0 & 48.4 & 53.5 \\
\hline BMI, kg/m² & $23.0 \pm 2.8$ & $22.2 \pm 2.9$ & $23.1 \pm 4.7$ & $20.1 \pm 2.7$ & - & $22.2 \pm 3.1$ \\
\hline \multicolumn{7}{|c|}{ Baseline BP, mmHg } \\
\hline SBP & $120.9 \pm 12.5$ & $107.6 \pm 11.1$ & $108.6 \pm 12.2$ & $102.7 \pm 10.7$ & $123.2 \pm 21.3$ & $110.9 \pm 13.3$ \\
\hline DBP & $78.9 \pm 8.3$ & $70.1 \pm 8.1$ & $70.6 \pm 6.9$ & $63.4 \pm 8.9$ & $70.5 \pm 10.5$ & $71.8 \pm 9.7$ \\
\hline MAP & $93.0 \pm 9.0$ & $82.6 \pm 8.7$ & $83.3 \pm 7.9$ & $76.5 \pm 9.2$ & $88.0 \pm 13.1$ & $84.8 \pm 10.4$ \\
\hline \multicolumn{7}{|c|}{ BP response to low-sodium intervention, $\mathrm{mmHg}$} \\
\hline SBP & $111.7 \pm 10.0^{*}$ & $103.4 \pm 9.1^{*}$ & $102.5 \pm 7.7^{*}$ & $100.3 \pm 9.4^{*}$ & - & $105.4 \pm 10.2^{*}$ \\
\hline DBP & $72.8 \pm 9.3^{*}$ & $66.4 \pm 7.7^{*}$ & $67.1 \pm 5.8^{\#}$ & $60.7 \pm 8.3^{*}$ & - & $67.5 \pm 9.1^{*}$ \\
\hline MAP & $85.7 \pm 9.0 *$ & $78.7 \pm 7.6^{*}$ & $78.9 \pm 5.4^{\#}$ & $73.9 \pm 8.3^{\#}$ & - & $80.1 \pm 9.0 *$ \\
\hline SBP change & $-8.65 \pm 9.52$ & $-3.90 \pm 5.41$ & $-6.15 \pm 7.88$ & $-2.38 \pm 4.79$ & - & $-5.20 \pm 7.31$ \\
\hline DBP change & $-6.00 \pm 6.71$ & $-3.64 \pm 4.83$ & $-3.48 \pm 6.36$ & $-2.70 \pm 5.21$ & - & $-4.19 \pm 5.69$ \\
\hline MAP change & $-6.88 \pm 7.07$ & $-3.73 \pm 4.55$ & $-4.37 \pm 6.52$ & $-2.59 \pm 4.56$ & - & $-4.53 \pm 5.73$ \\
\hline \multicolumn{7}{|c|}{ BP response to high-sodium intervention, $\mathrm{mmHg}$} \\
\hline SBP & $118.9 \pm 11.2$ & $108.5 \pm 11.1^{\#}$ & $108.4 \pm 10.9$ & $102.0 \pm 10.0$ & - & $110.6 \pm 12.4$ \\
\hline DBP & $76.2 \pm 8.1^{*}$ & $68.7 \pm 9.3^{*}$ & $68.6 \pm 7.5$ & $60.9 \pm 8.3^{*}$ & - & $69.8 \pm 10.0^{*}$ \\
\hline MAP & $90.4 \pm 8.5^{*}$ & $82.0 \pm 9.5$ & $81.9 \pm 8.0$ & $74.6 \pm 8.4^{*}$ & - & $83.4 \pm 10.4^{*}$ \\
\hline SBP change & $7.16 \pm 7.40$ & $5.09 \pm 6.50$ & $5.93 \pm 7.90$ & $1.72 \pm 4.07$ & - & $5.25 \pm 6.77$ \\
\hline DBP change & $3.49 \pm 7.33$ & $2.29 \pm 5.73$ & $1.51 \pm 4.69$ & $0.22 \pm 4.52$ & - & $2.30 \pm 6.12$ \\
\hline MAP change & $4.71 \pm 6.86$ & $3.22 \pm 5.60$ & $2.98 \pm 5.61$ & $0.72 \pm 3.79$ & - & $3.28 \pm 5.90$ \\
\hline \multicolumn{7}{|c|}{ BP response to high-sodium plus potassium intervention, $\mathrm{mmHg}$} \\
\hline SBP & $112.2 \pm 8.6^{*}$ & $103.1 \pm 8.9^{*}$ & $102.8 \pm 9.4^{*}$ & $101.0 \pm 9.6^{\#}$ & - & $105.5 \pm 10.0^{*}$ \\
\hline DBP & $73.0 \pm 7.7^{*}$ & $66.1 \pm 7.9^{*}$ & $65.9 \pm 7.1$ & $59.9 \pm 8.0^{*}$ & - & $67.2 \pm 8.9 *$ \\
\hline MAP & $86.1 \pm 7.4^{*}$ & $78.4 \pm 7.8^{*}$ & $78.2 \pm 7.2^{*}$ & $73.6 \pm 8.1^{*}$ & - & $79.9 \pm 8.8^{*}$ \\
\hline SBP change & $-6.54 \pm 5.65$ & $-5.48 \pm 5.86$ & $-5.59 \pm 7.10$ & $-1.02 \pm 4.15$ & - & $-5.13 \pm 5.90$ \\
\hline DBP change & $-3.21 \pm 4.76$ & $-2.63 \pm 4.88$ & $-2.69 \pm 4.42$ & $-1.02 \pm 4.25$ & - & $-2.56 \pm 4.76$ \\
\hline MAP change & $-4.32 \pm 4.40$ & $-3.58 \pm 4.77$ & $-3.66 \pm 5.05$ & $-1.02 \pm 3.35$ & - & $-3.42 \pm 4.60$ \\
\hline $\begin{array}{l}\text { Variables are } \mathrm{i} \\
\text { blood pressure } \\
P<0.01 \text { and }{ }^{\#} P\end{array}$ & $\begin{array}{l}\text { ed as mean } \\
\text { diastolic b }\end{array}$ & $\begin{array}{l}\text { andard dev } \\
\text { pressure; } \\
\text { aseline per } \\
\end{array}$ & BP, blood & $\begin{array}{l}\text { re; BMI, bc } \\
\text { sure. †All s }\end{array}$ & index; & $\begin{array}{l}\text { systolic } \\
\text { arents, * }\end{array}$ \\
\hline
\end{tabular}

Table 2. Influence of dietary intervention to urinary sodium and potassium excretions

\begin{tabular}{|c|c|c|c|c|c|}
\hline & Probands & Siblings & Spouses & Offspring & Total \\
\hline \multicolumn{6}{|l|}{ Baseline, mmol } \\
\hline 24 h Urinary sodium & $225 \pm 11.6$ & $213.8 \pm 16.4$ & $218.3 \pm 20.8$ & $205.4 \pm 23.4$ & $215.7 \pm 19.2$ \\
\hline $24 \mathrm{~h}$ Urinary potassium & $36.8 \pm 10.8$ & $38.1 \pm 9.1$ & $39.4 \pm 12.3$ & $35.8 \pm 15.7$ & $37.6 \pm 12.1$ \\
\hline \multicolumn{6}{|c|}{ Low-sodium intervention, mmol } \\
\hline $24 \mathrm{~h}$ Urinary sodium & $54.9 \pm 11.3^{*}$ & $53.6 \pm 9.8^{*}$ & $52.8 \pm 13.5^{*}$ & $58.2 \pm 15.1^{*}$ & $54.9 \pm 11.2^{*}$ \\
\hline $24 \mathrm{~h}$ Urinary potassium & $35.4 \pm 8.9^{\#}$ & $39.8 \pm 7.6^{\#}$ & $34.2 \pm 6.7 *$ & $40.5 \pm 9.8^{*}$ & $37.0 \pm 9.8$ \\
\hline \multicolumn{6}{|c|}{ High-sodium intervention, $\mathrm{mmol}$} \\
\hline $24 \mathrm{~h}$ Urinary sodium & $317.0 \pm 21.8^{*}$ & $304.4 \pm 28.6^{*}$ & $318.6 \pm 20.5^{*}$ & $298.4 \pm 25.1^{*}$ & $310.0 \pm 27.0^{*}$ \\
\hline $24 \mathrm{~h}$ Urinary potassium & $43.4 \pm 13.9 *$ & $39.6 \pm 9.1$ & $40.2 \pm 8.3$ & $41.1 \pm 14.5^{*}$ & $41.1 \pm 11.9 *$ \\
\hline \multicolumn{6}{|c|}{ High-sodium plus potassium-supplementation intervention, mmol } \\
\hline 24 h Urinary sodium & $319.8 \pm 24.2^{*}$ & $331.2 \pm 25.9 *$ & $324.7 \pm 28.4^{*}$ & $327.3 \pm 21.8^{*}$ & $325.8 \pm 27.4^{*}$ \\
\hline $24 \mathrm{~h}$ Urinary potassium & $86.8 \pm 9.6^{*}$ & $79.3 \pm 11.5^{*}$ & $94.6 \pm 12.9^{*}$ & $87.5 \pm 10.7^{*}$ & $87.1 \pm 12.9 *$ \\
\hline
\end{tabular}

Associations between SGK1 SNPS and BP responses to dietary intervention and baseline $B P$

The associations between SNPs and BP responses to low-sodium, high-sodium, and high-sodium plus potassium-supplementation interventions are shown in Table 4. SNP 


\section{Kidney \\ Blood Pressure Research}

Table 3. Information on Genotyped SNPs of SGK1

\begin{tabular}{cccccc}
\hline SNP & Region in Gene & Position & Alleles $^{\dagger}$ & MAF $^{\ddagger}$ & HW P-values $^{\ddagger}$ \\
\hline rs1763509 & Intron2 & 134554338 & $\mathrm{~A} / \mathrm{G}$ & 0.262431 & 0.0864 \\
rs4896033 & Intron2 & 134577726 & $\mathrm{G} / \mathrm{A}$ & 0.129121 & 0.4953 \\
rs9376026 & Intron1 & 134602454 & $\mathrm{C} / \mathrm{T}$ & 0.171271 & 0.376 \\
rs9389154 & Intron1 & 134614761 & $\mathrm{~A} / \mathrm{G}$ & 0.450549 & 0.3603 \\
rs4409196 & Intron1 & 134630634 & $\mathrm{C} / \mathrm{G}$ & 0.406077 & 0.7223 \\
rs3813344 & Exon1 & 134638966 & $\mathrm{G} / \mathrm{C}$ & 0.070225 & 0.8884 \\
\hline
\end{tabular}

SNP, single nucleotide polymorphism; MAF, Minor allele frequency; HW, HardyWeinberg equilibrium test. †Major allele/ minor allele. $\star$ parental generation.

Table 4. SNPs associated with BP Response to Dietary Intervention

\begin{tabular}{lccccccc}
\hline \multirow{2}{*}{ SNP } & \multirow{2}{*}{ Allele ${ }^{\dagger}$} & \multicolumn{2}{c}{ SBP response } & \multicolumn{2}{c}{ DBP response } & \multicolumn{2}{c}{ MAP response } \\
\cline { 2 - 8 } & & $\mathrm{Z}$ & $\mathrm{P}$-value & $\mathrm{Z}$ & P-value & $\mathrm{Z}$ & P-value \\
\hline Low-sodium & intervention & & & & & & \\
\hline rs1763509 & $\mathrm{G}$ & 0.178 & 0.859 & 1.007 & 0.314 & 0.773 & 0.44 \\
rs4896033 & $\mathrm{A}$ & 0.533 & 0.594 & -0.948 & 0.343 & -0.416 & 0.677 \\
rs9376026 & $\mathrm{T}$ & 0.258 & 0.796 & 2.359 & $\mathbf{0 . 0 1 8}$ & 2.286 & $\mathbf{0 . 0 2 2}$ a \\
rs9389154 & $\mathrm{G}$ & -0.262 & 0.793 & 0.023 & 0.981 & -0.098 & 0.922 \\
rs4409196 & $\mathrm{G}$ & -0.369 & 0.712 & -0.376 & 0.708 & -0.405 & 0.686 \\
rs3813344 & $\mathrm{C}$ & -0.657 & 0.511 & -0.696 & 0.487 & -0.751 & 0.453 \\
\hline High-sodium intervention & & & & & & \\
\hline rs1763509 & $\mathrm{G}$ & 0.386 & 0.700 & 0.430 & 0.667 & 0.443 & 0.658 \\
rs4896033 & $\mathrm{A}$ & 0.482 & 0.630 & -0.591 & 0.555 & -0.243 & 0.808 \\
rs9376026 & $\mathrm{T}$ & -0.030 & 0.976 & 0.412 & 0.681 & 0.291 & 0.771 \\
rs9389154 & $\mathrm{G}$ & 0.383 & 0.701 & 0.119 & 0.905 & 0.223 & 0.823 \\
rs4409196 & $\mathrm{G}$ & 0.732 & 0.464 & 0.258 & 0.796 & 0.447 & 0.655 \\
rs3813344 & $\mathrm{C}$ & 0.207 & 0.836 & 0.145 & 0.884 & 0.18 & 0.858 \\
\hline High-sodium plus potassium supplementation intervention & & \\
\hline rs1763509 & $\mathrm{G}$ & -0.491 & 0.623 & -0.005 & 0.996 & -0.191 & 0.849 \\
rs4896033 & $\mathrm{A}$ & 0.472 & 0.637 & 0.864 & 0.388 & 0.826 & 0.409 \\
rs9376026 & $\mathrm{T}$ & 0.178 & 0.859 & -1.293 & 0.196 & -0.896 & 0.37 \\
rs9389154 & $\mathrm{G}$ & -1.762 & $\mathbf{0 . 0 7 8}$ & 0.694 & 0.488 & -0.044 & 0.964 \\
rs4409196 & $\mathrm{G}$ & -0.963 & 0.336 & 1.110 & 0.267 & 0.435 & 0.664 \\
rs3813344 & $\mathrm{C}$ & -0.901 & 0.368 & -0.476 & 0.634 & -0.681 & 0.496 \\
\hline
\end{tabular}

For associations that were not significant under any model (additive model, dominant model and recessive model), $\mathrm{Z}$ and $\mathrm{P}$ values for an additive model are listed. All genetic models are based on the minor allele of each SNP. SNP, single nucleotide polymorphism; SBP, systolic blood pressure; DBP, diastolic blood pressure; MAP, mean arterial pressure; $\mathrm{Z}$ indicates test statistic for Family-Based Association Test(FBAT); P-values are corrected for multiple testing $(\mathrm{FDR}<0.05) .{ }^{+}$minor allele, a additive model, c recessive model.

rs9376026 was significantly associated with DBP and MAP responses to low-sodium intervention ( $\mathrm{P}=0.018$ and $\mathrm{P}=0.022$, respectively) after adjustment for multiple testing. Regretfully, associations between the six SNPs and BP responses to high-sodium and highsodium plus potassium-supplementation interventions did not reach nominal statistical significance. In addition, Haploview software was used to construct haplotype blocks of the six SNPs, but none were constructed because of the weak LD between these SNPs in the study participants (Figure 1). Therefore, the associations of the SGK1 haplotypes with BP responses to dietary intervention could not be analyzed further. 


\section{Kidney Blood Pressure Research}

Fig. 1. Linkage disequilibrium structure of the SGK1 gene. The black boxes in gene represent exons. Solid lines show introns and dashed lines show gene flanking regions. pairwise linkage disequilibrium (LD) coefficients $\mathrm{D}^{\prime} \times 100$ are shown in each cell (D'values of 1.0 are not shown) and The $r^{2}$ color scheme of Haploview was applie$\mathrm{d}\left(\mathrm{r}^{2}=0\right.$ shown in white, $0<\mathrm{r}^{2}$ $<1$ shown in shades of gray, and $r^{2}=1$ shown in black).

\section{Kidney Blood Press Res 2015;40:424-434}

DOI: 10.1159/000368518

Published online: July 31, 2015

(C) 2015 S. Karger AG, Basel

www.karger.com/kbr

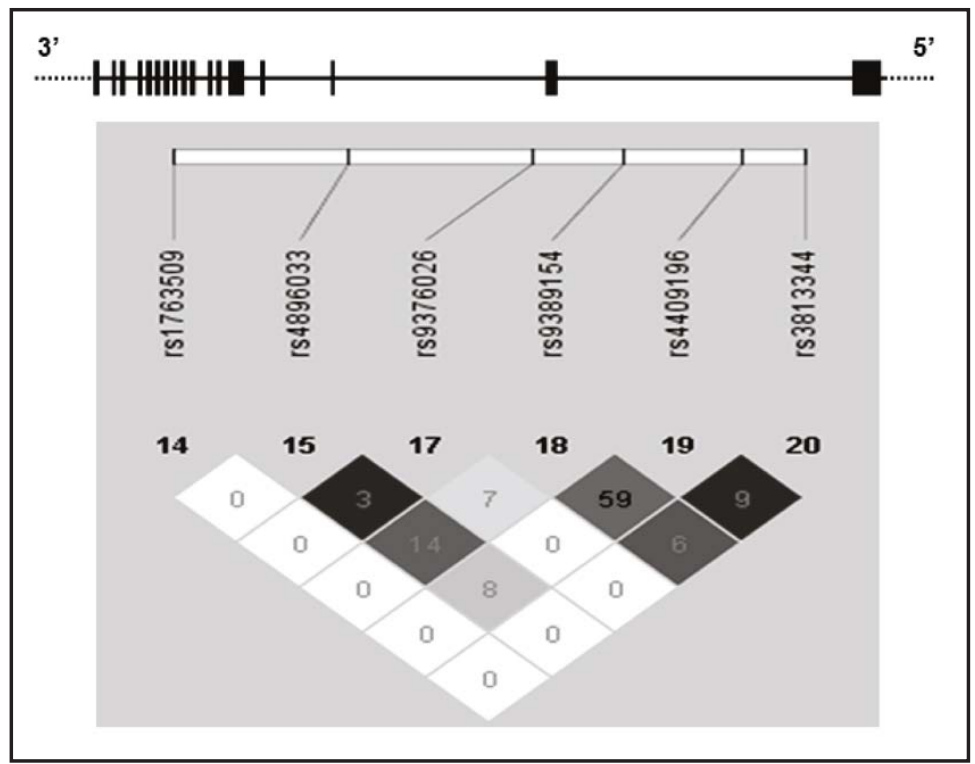

Table 5. SNPs significantly associated with basal BP

\begin{tabular}{cccccccc}
\hline \multirow{2}{*}{ SNP } & \multirow{2}{*}{ Alleles $^{\dagger}$} & \multicolumn{2}{c}{ SBP } & \multicolumn{2}{c}{ DBP } & \multicolumn{2}{c}{ MAP } \\
\cline { 3 - 8 } & & $\mathrm{Z}$ & $\mathrm{P}$-value & $\mathrm{Z}$ & $\mathrm{P}$-value & $\mathrm{Z}$ & P-value \\
\hline rs1763509 & $\mathrm{G}$ & -0.553 & 0.581 & 2.142 & $\mathbf{0 . 0 3 2}$ & -0.346 & 0.730 \\
rs4896033 & $\mathrm{A}$ & 0.593 & 0.553 & 0.266 & 0.790 & 0.424 & 0.672 \\
rs9376026 & $\mathrm{T}$ & 1.079 & 0.281 & 2.157 & $\mathbf{0 . 0 3 1}^{\mathbf{c}}$ & 1.526 & 0.127 \\
rs9389154 & $\mathrm{G}$ & 2.052 & $\mathbf{0 . 0 4}^{\mathbf{b}}$ & 0.331 & 0.741 & -0.127 & 0.899 \\
rs4409196 & $\mathrm{G}$ & -0.673 & 0.501 & 0.096 & 0.923 & -0.23 & 0.818 \\
rs3813344 & $\mathrm{C}$ & -1.960 & $\mathbf{0 . 0 4 9}$ & -2.43 & $\mathbf{0 . 0 1 5}^{\mathbf{a}}$ & -2.362 & $\mathbf{0 . 0 1 8}$ \\
\hline
\end{tabular}

For associations that were not significant under any model (additive model, dominant model and recessive model), $\mathrm{Z}$ and $\mathrm{P}$ values for an additive model are listed. All genetic models are based on the minor allele of each. Abbreviations as in Table 4, $†$ minor allele, a additive model, $\mathrm{b}$ dominant model, $\mathrm{c}$ recessive model.

Table 5 shows the associations of the SNPs with the baseline SBP, DBP, and MAP of the study participants. After adjustment for multiple testing, SGK1 SNP rs9389154 and two other SNPs (rs1763509 and rs9376026) were respectively associated with baseline SBP and DBP $(\mathrm{P}=0.040,0.032$ and 0.031 , respectively). SGK1 SNP rs3813344 was significantly associated with baseline SBP, DBP, and MAP ( $\mathrm{P}=0.049,0.015$ and 0.018 , respectively).

\section{Discussion}

In this study, we identified several genetic variants in the SGK1 gene that may play an important role in basal BP and BP responses to dietary sodium intake. SNP rs9376026 of the SGK1 gene showed a significant influence on DBP and MAP responses to low-sodium intervention. SNP rs9389154 and two other SNPs (rs1763509 and rs9376026) were also respectively associated with SBP and DBP at baseline. SNP rs3813344 in the SGK1 gene was significantly associated with baseline SBP, DBP, and MAP. These findings may help us gain a better understanding of the genetic mechanisms underlying BP regulation. 


\section{Kidney Blood Pressure Research}

Kidney Blood Press Res 2015;40:424-434

DOI: $10.1159 / 000368518$

Published online: July 31, 2015

(C) 2015 S. Karger AG, Base

www.karger.com/kbr

In vivo, SGK1 stimulates renal sodium reabsorption as well as salt appetite thus affecting BP $[27,28]$. The effects of this kinase are observed in SGK1\% mouse. Under a standard $\mathrm{Na}^{+}$ diet, the renal water and $\mathrm{Na}^{+} / \mathrm{K}^{+}$excretions in doxycycline-treated kidney-specific SGK1 $\%$ mice have a tendency to be higher than those in wild-type control mice, whereas under a low- $\mathrm{Na}^{+}$diet, the SGK1\% mice have lower BP, increased $\mathrm{Na}^{+}$excretion, and hyperkalemia [16]. Ackermann and colleagues tested the in vivo efficacy of a novel SGK1 inhibitor (EMD638683) in mice and found that it could significantly decrease BP in fructose/saline-treated mice but not in SGK1 $\%$ mice or in control animals [29]. In addition, the role of SGK1 in BP regulation was demonstrated in studies on SGK1 gene polymorphism. A previous study reported that a genotype combination [the intron 6 (I6CC) and the exon 8 (E8CC/CT)] in the SGK1 gene was associated with moderately enhanced BP in 232 non-obese, normotensive white Germans [30]. Wowern et al. [31] conducted a cross-sectional study of 4608 unrelated subjects (2996 hypertensive patients and 1612 normotensive subjects) to verify this finding, and reached a consistent conclusion. In the current study, we first explored the association between SGK1 gene polymorphisms and baseline BP of a Chinese Han population, and then found that four SNPs (rs9389154, rs1763509, rs9376026 and rs3813344) in the SGK1 gene were significantly associated with BP, which provided further evidence of the participation of the SGK1 gene in BP regulation.

SGK1 gene polymorphisms are closely related to BP, and may play an important role in the salt sensitivity of BP. Rao et al. [32] found that two SGK1 genetic variants (rs2758151 and rs9402571) were associated with SBP response to high-sodium intervention in a Caucasian population. An association between SGK1 marker rs2758151 and BP response to salt dietary intervention in a homogenous Han Chinese population was also demonstrated by Li and colleagues [33]. However, SNP rs2758151, as reported by Li et al. [33], was associated with DBP response rather than with SBP response, as reported by Rao et al. [32]. The differences in study populations, and racial and intervention methods adopted in the two studies may have caused the discrepant results. In the present study, rs9376026 in the SGK1 gene was found to be significantly associated with DBP and MAP responses to low-sodium intervention. This gene locus was also examined in Li's study [31], but no statistically significant association was found between this locus and BP response to low- or high-sodium intervention. The discrepancy could be due to the different study populations or small sample size in our study. Further studies are needed to validate the role of this gene locus in the salt sensitivity of BP. Although the aforementioned findings vary, all of them suggest that the common variants of the SGK1 gene may play an important role in determining BP response to dietary sodium intake.

Epidemiology studies suggested that dietary potassium intake is inversely related to BP, and $\mathrm{BP}$ responses to the potassium intake of individuals within populations are heterogeneous $[5,6]$. Previous evidence indicated that SGK1 is also a regulator of renal potassium excretion and, therefore, of potassium homeostasis in the body. Huang et al. [34] reported that plasma $\mathrm{K}^{+}$concentration in wild-type mice was not significantly modified by either a high or low $\mathrm{K}^{+}$ diet. However, in Sgk1 $1^{--}$mice, a high $\mathrm{K}^{+}$diet significantly enhanced plasma $\mathrm{K}^{+}$concentration, despite plasma aldosterone concentration reaching values about sixfold higher than in wildtype mice. Significant association of SNPs in APLN and ACE2 genes with BP response to dietary potassium supplementation were also found in the Gensalt study [7]. Gu and colleagues showed that a moderate heritability of BP response to potassium supplementation existed in a Chinese population [21]. These studies suggested that genetic factors may contribute to the variation in BP responses to potassium intake. Given the important role of SGK1 in BP regulation and $\mathrm{K}^{+}$metabolism, the SGK1 gene polymorphisms may also have a significant influence on BP response to dietary potassium supplementation. In the first investigation on the association between SGK1 genetic variants and BP response to potassium intake in a 


\section{Kidney \\ Blood Pressure Research}

Kidney Blood Press Res 2015;40:424-434

\begin{tabular}{l|l}
\hline DOI: $10.1159 / 000368518$ & C 2015 S. Karger AG, Basel \\
\hline
\end{tabular}

Published online: July 31, 2015

www.karger.com/kbr

Chinese Han population, we observed an association between rs9389154 and SBP response, albeit not significant. Large multi-center studies are necessary to confirm the role of SGK1 gene polymorphisms on BP responses to potassium intervention.

Our study possesses several strengths. First, our study was carried out in a Chinese Han population. Thus, the bias caused by population stratification is unlikely. Study participants who live in a homogenous environment have similar lifestyles and eating habits. BP responses to dietary intervention were also measured under a controlled dietary sodium intake or potassium supplementation. Thus phenotypic variance caused by environmental factors is reduced. Finally, compliance with a dietary intervention program assessed by 24hour urinary sodium and potassium excretions was excellent. Despite its strengths, this study also has limitations. As the findings were derived from a Chinese Han population, they may not be generalizable to other populations because of the underlying differences in LD structure. Therefore, our findings need to be validated or replicated in different populations. Furthermore, aldosterone participates in the regulation of SGK1 expression and activity. However, the plasma or urinary concentration of aldosterone was not measured, and thus the relationship of SGK1 genotype with aldosterone level could not established. As the molecular consequences of the SNPs are still unclear, further functional studies are also needed to clarify the influence of each SNP on SGK1.

\section{Conclusion}

Our study identified that the genetic polymorphism in SGK1 gene is significantly associated with BP responses to dietary sodium intervention. The results of our study suggested that the SGK1 gene may be mechanistically involved in salt-sensitivity phenotypes.

\section{Disclosure Statement}

The authors declared no conflict of interest. We emphasize that we referred to the subject dietary intervention methods adopted in the Gensalt study.

\section{Acknowledgements}

This work was supported by the grant 2012CB517804 from the National Program on Key Basic Research Project of China (973 Program) and fund 81370357 from the National Science Foundation of China.

\section{References}

1 Lawes CM, Vander HS, Rodgers A: Global burden of blood-pressure-related disease, 2001. Lancet 2008;371:1513-1518.

2 Aburto NJ, Hanson S, Gutierrez H, Hooper L, Elliott P, Cappuccio FP: Effect of increased potassium intake on cardiovascular risk factors and disease: systematic review and meta-analyses. BMJ 2013;346:f1378.

3 Aburto NJ, Ziolkovska A, Hooper L, Elliott P, Cappuccio FP, Meerpohl JJ: Effect of lower sodium intake on health: systematic review and meta-analyses. BMJ 2013;346:f1326.

4 Mente A, O'Donnell MJ, Rangarajan S, McQueen MJ, Poirier P, Wielgosz A, Morrison H, Li W, Wang X, Di C, Mony P, Devanath A, Rosengren A, Oguz A, Zatonska K, Yusufali AH, Lopez-Jaramillo P, Avezum A, Ismail N, Lanas F, Puoane T, Diaz R, Kelishadi R, Iqbal R, Yusuf R, Chifamba J, Khatib R, Teo K, Yusuf S: Association of urinary sodium and potassium excretion with blood pressure. N Engl J Med 2014;371:601-611. 


\section{Kidney \\ Blood Pressure Research}

Kidney Blood Press Res 2015;40:424-434

\begin{tabular}{l|l}
\hline DOI: $10.1159 / 000368518$ & (C) 2015 S. Karger AG, Basel
\end{tabular}

Published online: July 31, 2015

www.karger.com/kbr

5 Geleijnse JM, Kok FJ, Grobbee DE: Blood pressure response to changes in sodium and potassium intake: a metaregression analysis of randomised trials. J Hum Hypertens 2003;17:471-480.

6 Chen J: Sodium sensitivity of blood pressure in Chinese populations. Curr Hypertens Rep 2010;12:127-134.

7 Zhao Q, Gu D, Kelly TN, Hixson JE, Rao DC, Jaquish CE, Chen J, Huang J, Chen CS, Gu CC, Whelton PK, He J: Association of genetic variants in the apelin-APJ system and ACE2 with blood pressure responses to potassium supplementation: the GenSalt study. Am J Hypertens 2010;23:606-613.

8 Firestone GL, Giampaolo JR, O'Keeffe BA: Stimulus-dependent regulation of serum and glucocorticoid inducible protein kinase (SGK) transcription, subcellular localization and enzymatic activity. Cell Physiol Biochem 2003;13:1-12.

9 Webster MK, Goya L, Ge Y, Maiyar AC, Firestone GL: Characterization of sgk, a novel member of the serine/ threonine protein kinase gene family which is transcriptionally induced by glucocorticoids and serum. Mol Cell Biol 1993;13:2031-2040.

10 Waldegger S, Barth P, Raber G, Lang F: Cloning and characterization of a putative human serine/threonine protein kinase transcriptionally modified during anisotonic and isotonic alterations of cell volume. Proc Natl Acad Sci USA 1997;94:4440-4445.

11 Voelkl J, Mia S, Meissner A, Ahmed MS, Feger M, Elvira B, Walker B, Alessi DR, Alesutan I, Lang F: PKB/SGKresistant GSK-3 signaling following unilateral ureteral obstruction. Kidney Blood Press Res 2013;38:156164.

12 Towhid ST, Liu GL, Ackermann TF, Beier N, Scholz W, Fuchss T, Toulany M, Rodemann HP, Lang F: Inhibition of colonic tumor growth by the selective SGK inhibitor EMD638683. Cell Physiol Biochem 2013;32:838848.

13 Borst O, Schaub M, Walker B, Schmid E, Munzer P, Voelkl J, Alesutan I, Rodriguez JM, Vogel S, Schoenberger T, Metzger K, Rath D, Umbach A, Kuhl D, Muller II, Seizer P, Geisler T, Gawaz M, Lang F: Pivotal role of serum- and glucocorticoid-inducible kinase 1 in vascular inflammation and atherogenesis. Arterioscler Thromb Vasc Biol 2015;35:547-557.

14 Zecevic M, Heitzmann D, Camargo SM, Verrey F: SGK1 increases Na,K-ATP cell-surface expression and function in Xenopus laevis oocytes. Pflugers Arch 2004;448:29-35.

15 Wang D, Sun H, Lang F, Yun CC: Activation of NHE3 by dexamethasone requires phosphorylation of NHE3 at Ser663 by SGK1. Am J Physiol Cell Physiol 2005;289:C802-810.

16 Arroyo JP, Lagnaz D, Ronzaud C, Vazquez N, Ko BS, Moddes L, Ruffieux-Daidie D, Hausel P, Koesters R, Yang B, Stokes JB, Hoover RS, Gamba G, Staub O: Nedd4-2 modulates renal Na+-Cl- cotransporter via the aldosterone-SGK1-Nedd4-2 pathway. J Am Soc Nephrol 2011;22:1707-1719.

17 Soundararajan R, Pearce D, Ziera T: The role of the ENaC-regulatory complex in aldosterone-mediated sodium transport. Mol Cell Endocrinol 2012;350:242-247.

18 Zhou X, Zhang Z, Shin MK, Horwitz SB, Levorse JM, Zhu L, Sharif-Rodriguez W, Streltsov DY, Dajee M, Hernandez M, Pan Y, Urosevic-Price O, Wang L, Forrest G, Szeto D, Zhu Y, Cui Y, Michael B, Balogh LA, Welling PA, Wade JB, Roy S, Sullivan KA: Heterozygous disruption of renal outer medullary potassium channel in rats is associated with reduced blood pressure. Hypertension 2013;62:288-294.

19 Faresse N, Lagnaz D, Debonneville A, Ismailji A, Maillard M, Fejes-Toth G, Naray-Fejes-Toth A, Staub 0: Inducible kidney-specific Sgk1 knockout mice show a salt-losing phenotype. Am J Physiol Renal Physiol 2012;302:F977-985.

20 Busjahn A, Luft FC: Twin studies in the analysis of minor physiological differences between individuals: Cell Physiol Biochem 2003;13:51-58.

21 Gu D, Rice T, Wang S, Yang W, Gu C, Chen CS, Hixson JE, Jaquish CE, Yao ZJ, Liu DP, Rao DC, He J: Heritability of blood pressure responses to dietary sodium and potassium intake in a Chinese population. Hypertension 2007;50:116-122.

22 Perloff D, Grim C, Flack J, Frohlich ED, Hill M, McDonald M, Morgenstern BZ: Human blood pressure determination by sphygmomanometry. Circulation 1993;88:2460-2470.

23 Purcell S, Neale B, Todd-Brown K, Thomas L, Ferreira MA, Bender D, Maller J, Sklar P, de Bakker PI, Daly MJ, Sham PC: PLINK: a tool set for whole-genome association and population-based linkage analyses. Am J Hum Genet 2007;81:559-575.

24 Barrett JC, Fry B, Maller J, Daly MJ: Haploview: analysis and visualization of LD and haplotype maps. Bioinformatics 2005;21:263-265. 


\section{Kidney \\ Blood Pressure Research}

\section{Kidney Blood Press Res 2015;40:424-434}

DOI: $10.1159 / 000368518$

Published online: July 31, 2015

(C) 2015 S. Karger AG, Basel

www.karger.com/kbr

Chu/Wang/Wang/Mu/Liu/Wang/Ren/Wang/Yuan: SGK1 and BP Responses to Dietary Interventions

25 Horvath S, Xu X, Laird NM: The family based association test method: strategies for studying general genotype--phenotype associations. Eur J Hum Genet 2001;9:301-306.

26 Benjamini Y, Hochberg Y: Controlling the false discovery rate: a practical and powerful approach to multiple testing. J R Stat Soc Ser B 1995;57:298-300.

27 Wulff P, Vallon V, Huang DY, Volkl H, Yu F, Richter K, Jansen M, Schlunz M, Klingel K, Loffing J, Kauselmann G, Bosl MR, Lang F, Kuhl D: Impaired renal $\mathrm{Na}(+)$ retention in the sgk1-knockout mouse. J Clin Invest 2002;110:1263-1268.

28 Vallon V, Huang DY, Grahammer F, Wyatt AW, Osswald H, Wulff P, Kuhl D, Lang F: SGK1 as a determinant of kidney function and salt intake in response to mineralocorticoid excess. Am J Physiol Regul Integr Comp Physiol 2005;289:R395-395R401.

29 Ackermann TF, Boini KM, Beier N, Scholz W, Fuchss T, Lang F: EMD638683, a novel SGK inhibitor with antihypertensive potency. Cell Physiol Biochem 2011;28:137-146.

30 Busjahn A, Aydin A, Uhlmann R, Krasko C, Bahring S, Szelestei T, Feng Y, Dahm S, Sharma AM, Luft FC, Lang F: Serum- and glucocorticoid-regulated kinase (SGK1) gene and blood pressure. Hypertension 2002;40:256-260.

31 von WF, Berglund G, Carlson J, Mansson H, Hedblad B, Melander O: Genetic variance of SGK-1 is associated with blood pressure, blood pressure change over time and strength of the insulin-diastolic blood pressure relationship. Kidney Int 2005;68:2164-2172.

32 Rao AD, Sun B, Saxena A, Hopkins PN, Jeunemaitre X, Brown NJ, Adler GK, Williams JS: Polymorphisms in the serum- and glucocorticoid-inducible kinase 1 gene are associated with blood pressure and renin response to dietary salt intake. J Hum Hypertens 2013;27:176-180.

33 Li C, Yang X, He J, Hixson JE, Gu D, Rao DC, Shimmin LC, Huang J, Gu CC, Chen J, Li J, Kelly TN: A genebased analysis of variants in the serum/glucocorticoid regulated kinase (SGK) genes with blood pressure responses to sodium intake: the GenSalt Study. PLoS One 2014;9:e98432.

34 Huang DY, Wulff P, Volkl H, Loffing J, Richter K, Kuhl D, Lang F, Vallon V: Impaired regulation of renal K+ elimination in the sgk1-knockout mouse. J Am Soc Nephrol 2004;15:885-891. 